\title{
Anticorrosion properties of Epoxidized Palm Olein/Epoxy Resin as Coating Materials on Low-Carbon Steel in 3.5\% NaCl
}

\author{
Fan Zhenyu*, Xu Qing, Xu Yang, Lin Nan \\ ${ }^{1}$ Qiqihaer University, College of Life Sciences, Agriculture and Forestry, 161006, Qiqihar, China \\ ${ }^{2}$ Heilongjiang Provincial Key Laboratory of Resistance Gene Engineering and Preservation of \\ Biodiversity in Cold Areas, 161006, Qiqihar, China \\ *E-mail: zhengyu fan88@163.com
}

doi: $10.20964 / 2019.08 .93$

Received: 9 April 2019 / Accepted: 12 June 2019 / Published: 30 June 2019

\begin{abstract}
Epoxy resins are valued for their excellent toughness and adhesive strength, which are contributing factors in determining a coating lifespan in aggressive environments. With new challenges in the oil and gas industry, polymers derived from petrochemical-based definitely have become major concern to the affected industry. Using epoxididized palm olein (EPO) is one of the alternative in the epoxy resins as minor substitution. This project aims to study the effects of mixing EPO into the conventional epoxy in terms of corrosion resistance. Coating performance was evaluated by comparing conventional epoxy and EPO using low-carbon steel as sample. Electrochemical impedance spectroscopy (EIS) and immersion test was conducted using $3.5 \% \mathrm{NaCl}$ to study the effect of corrosion and weight loss on the low-carbon steel. The results indicated that a small amount $(20 \%)$ of the EPO is still acceptable in terms of cost optimization but reduced the coating performance. However, too much of EPO (40\%) had led to accumulation which hinder the coating performance and increased dry film thickness. Furthermore, the resistance against corrosion was affected with additional amount of EPO at 16\% reduce (20\% EPO) and 95\% reduce (40\% EPO) with respect to the conventional epoxy. In terms of cost optimization, the overall cost could be reduced by $13 \%$.
\end{abstract}

Keywords: Epoxidized palm olein; Epoxy resin; Electrochemical impedance spectroscopy; Corrosion resistance; Weight loss.

\section{FULL TEXT}

(C) 2019 The Authors. Published by ESG (www.electrochemsci.org). This article is an open access article distributed under the terms and conditions of the Creative Commons Attribution license (http://creativecommons.org/licenses/by/4.0/). 